\title{
Use of streptokinase to aid in drainage of postoperative pericardial effusion
}

\author{
JUDITH H CROSS, JOSEPH V DE GIOVANNI, ERIC D SILOVE \\ From the Department of Cardiology, Children's Hospital, Birmingham
}

SUMMARY A case of cardiac tamponade secondary to a late, loculated pericardial effusion after open pulmonary valvotomy is described. Percutaneous drainage of the effusion was aided by the infusion of intrapericardial streptokinase.

Pericardial effusion causing cardiac tamponade occurs in quite a few patients after open heart surgery. Rapid diagnosis and treatment are essential to prevent the associated high morbidity. Loculation of fluid may hinder drainage and relief. We report a case in which percutaneous infusion of a fibrinolytic agent aided drainage of such an effusion and may have prevented reaccumulation of fluid.

\section{Case report}

A boy with Noonan's syndrome presented with severe valvar pulmonary stenosis and hypertrophic obstructive cardiomyopathy when he was 15 months old. Balloon dilatation of the pulmonary valve at the age of 16 months resulted in only a slight reduction in gradient. He, therefore, underwent open pulmonary valvotomy with right ventricular homograft patch four months later.

Although he had coexistent interstitial pneumonitis (requiring low dose oral prednisolone) he initially did well and was extubated on the eighth postoperative day. A mild degree of heart failure responded promptly to diuretic treatment. Steroid treatment was maintained throughout. On day 16, however, tachypnoea developed with faint heart sounds and hepatomegaly. There was no pyrexia or leucocytosis at any time. An echocardiogram showed a large pericardial effusion of depth $1.5 \mathrm{~cm}$ posterior

Requests for reprints to Dr Judith H Cross, Birmingham Children's Hospital, Ladywood Middleway, Birmingham B16 8ET. to the left ventricle; this was best seen on the left parasternal short axis view. Straw coloured fluid (75 ml) was drained percutaneously. Repeat echocardiography showed a reduction in effusion depth to $0.96 \mathrm{~cm}$. Initially he improved but on day 21 he deteriorated quite suddenly with clinical signs of cardiac tamponade.

The recurrence of a large pericardial effusion (depth $2.8 \mathrm{~cm}$ ) posterior to the left ventricle with cardiac compression was confirmed on the echocardiogram. On this occasion thick fibrinous strands could be seen traversing the pericardial space (figs 1

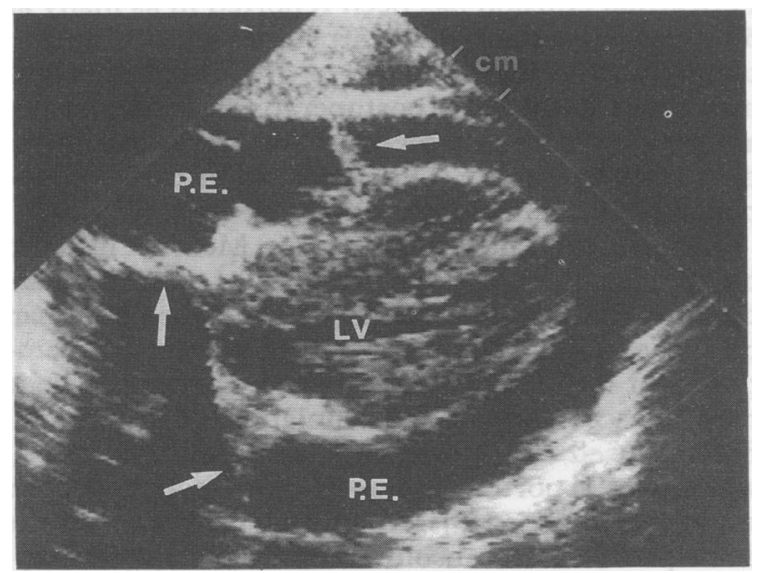

Fig 1 Short axis view across body of left ventricle showing large pericardial effusion with fibrin strands (arrowed). Concentric hypertrophy of the left ventricle is present. $P E$, pericardial effusion; $L V$, left ventricle. 


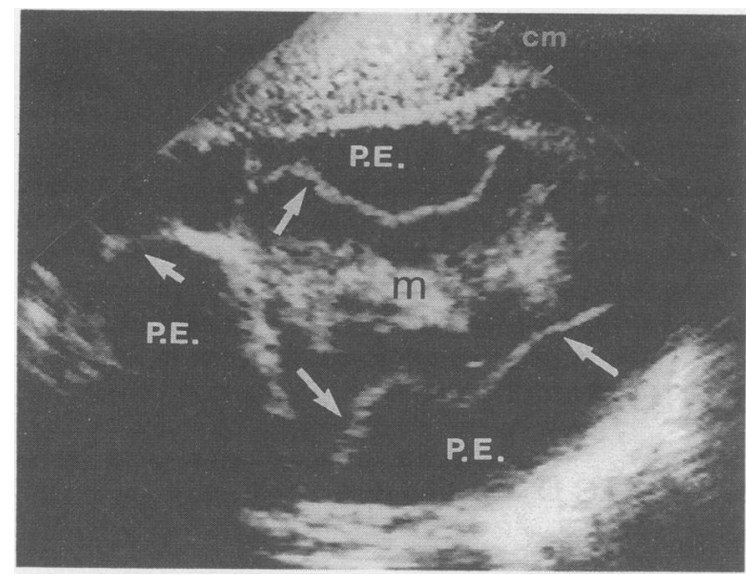

Fig 2 Short axis cut close to cardiac apex showing loculation of large pericardial effusion by fibrin (arrowed). $M$, apical myocardium; $P E$, pericardial effusion.

and 2). A cannula was inserted into the pericardium percutaneously from below the xiphisternum, and $130 \mathrm{ml}$ of bloodstained fluid was withdrawn. The cannula was left in place and allowed to drain. A further $40 \mathrm{ml}$ was withdrawn four hours later, and then 2000 units of streptokinase was infused into the pericardial sac. The drain was clamped for three hours and then allowed to drain freely. The next day a further 2000 units of streptokinase was infused. The drain was removed on day 23. Repeat echocardiograms on days 23,25 , and 38 showed no reaccumulation of pericardial fluid.

\section{Discussion}

Pericardial effusion has been reported in as many as $56 \%$ patients after open heart surgery, ${ }^{1}$ with cardiac tamponade occurring in up to $4 \%$. Such effusions may occur in the early postoperative period, usually associated with acute bleeding, or more than seven days after operation. The incidence of cardiac tamponade in late effusions is only $0.25-2.6 \%{ }^{2}$

Late effusions have many causes. Most are likely to be the result of residual thrombus after pericardiotomy. ${ }^{2}$ Thrombus has a higher osmolality than plasma and draws fluid from the intravascular compartment into the pericardial space. Some effusions may be secondary to accumulation of pericardial fluid caused by post-pericardiotomy syndrome, which was reported in $1.6-50 \%$ of patients ${ }^{34}$; the wide variation in this frequency probably results from problems in absolute definition and overlap. The diagnosis of cardiac tamponade may be confused with congestive cardiac failure. Cross sectional echocardiography is usually diagnostic, but pericardial clot compression without fluid may cause tam- ponade and can be difficult to identify by echocardiography. Rapid diagnosis and effective management of cardiac tamponade are essential because outcome can be fatal.

Our patient did not have a pericardial effusion in the immediate postoperative period but signs of cardiac tamponade, requiring drainage, developed on day 16. On further accumulation of fluid, fibrinous organisation of the effusion was noted on cross sectional echocardiography. The child showed no signs of postpericardiotomy syndrome such as fever, apparent pain, or leucocytosis. Steroids may have suppressed these signs, but they should also have suppressed any inflammatory process causing accumulation of pericardial fluid. The fibrinous strands suggested that organised thrombus was the likeliest cause. Complete drainage of fluid was prevented by loculation and reaccumulation of the effusion was likely.

Streptokinase has been used intrapleurally for over 30 years to aid drainage of loculated empyema, ${ }^{5}$ without inducing any systemic fibrinolytic effect. ${ }^{6}$ There is one report of haemorrhage after intrapleural administration but the existence of a bronchopleural fistula may have predisposed the patient to systemic absorption of streptokinase. ${ }^{7}$ After forming a complex with plasminogen, streptokinase combines with fibrin and activates subsequent thrombolysis. In our patient, intrapericardial infusion of streptokinase aided effective percutaneous drainage of an organised pericardial effusion, with relief of cardiac tamponade, and it may also have prevented a recurrence. We suggest that intrapericardial streptokinase has a role in the management of late postoperative pericardial effusions, particularly when fluid is loculated by fibrin strands. None the less, the technique should not be used where there is evidence of inflammation, which may enhance absorption of the enzyme and increase the risk of haemorrhage.

We thank Mr L D Abrams for his advice on the management with extravascular streptokinase.

\section{References}

1 Stevenson LW, Child JS, Laks N, Kern L. Incidence and significance of early pericardial effusions after cardiac surgery. Am J Cardiol 1984;54:848-51.

2 Barkin AM, Schaff HV, Gardner TJ, et al. Diagnosis and management of post-operative pericardial effusions and late cardiac tamponade following open heart surgery. Ann Thorac Surg 1981;31:512-9.

3 Scott RAP, Drew CE. Delayed pericardial effusion with tamponade after cardiac surgery. Br Heart $J$ 1973;35:1304-6.

4 Ofori-Krakye SK, Tyberry TI, Geha AS, Hammond 
GL, Cohen LS, Langan RA. Late cardiac tamponade after open heart surgery: incidence, role of anticoagulants in its pathogenesis and its relationship to the post-pericardiotomy syndrome. Circulation $1981 ; 63 ; 1323-8$.

5 Tillett WS, Sherry S, Read T. The use of Streptokinase-Streptodornase in the treatment of postpneumonic empyema. J Thorac Cardiovasc Surg
1951;21:275-97.

6 Berglin E, Ekroth R, Teger-Nilson AC, WilliamOlsson G. Intrapleural instillation of Streptokinase: effects on systemic fibrinolysis. Thorac Cardiovasc Surg 1981;29:124-6.

7 Godley PJ, Bell RC. Major haemorrhage following administration of intrapleural Streptokinase. Chest 1984;86:486-7. 